\title{
Editorial 31(5): Special issue on educational design research (EDR) in post-secondary learning environments
}

\author{
Theodore J. Kopcha \\ University of Georgia \\ Matthew M. Schmidt \\ University of Cincinnati \\ Susan McKenney \\ University of Twente \\ Open University of the Netherlands
}

\section{Introduction}

Along with many ASCILITE members, we have grown increasingly concerned that current approaches to educational technology research lack value and practical application in the field. Educational design research (EDR) is an emerging approach that bridges the demand for rigorous research with the development of relevant solutions to educational problems. EDR is an intervention and process-oriented approach that uses a variety of methods to examine the development and implementation of instructional solutions to current educational problems. As evidence about the inner workings of interventions accumulates over time, design principles and learning theories are derived from work in local contexts, and their limits can be tested in other settings. This genre of research is currently underrepresented in the literature. To advance scholarship through the execution and reporting of EDR, we identified an urgent need for examples across fields, and especially related to educational technology in higher education.

\section{What is educational design research?}

EDR constitutes a family of design-oriented approaches to educational research, including but not limited to design-based research (DBR) (Barab \& Squire, 2004), design and development research (DDR) (Richey \& Klein, 2014), and design-based implementation research (DBIR) (Penuel, Fishman, Cheng, \& Sabelli, 2011). Although enormous variation in design studies exists, several core elements are common across most projects. As shown in Figure 1, a generic model for EDR, three phases are central: analysis and exploration, design and construction, and evaluation and reflection. Analysis and exploration studies focus on understanding educational problems through analysis of the literature, stakeholders, and context (e.g., Vanderhoven, Schellens, Valcke, \& Raes, 2014). Design and construction studies focus on presenting design frameworks along with the theoretical and empirical grounding that gives them shape (e.g., Herrington \& Oliver, 2000; Raval, McKenney, \& Pieters, 2010). Finally, evaluation and reflection studies describe the practical and scientific implications that result from formative and/or summative evaluations of designed interventions (e.g., Bakah, Voogt, \& Pieters, 2012; Barab, Sadler, Heiselt, Hickey, \& Zuiker, 2007). Each of these phases features bilateral interaction with practice, through activities that support implementation and spread, which increase as the project matures. By positioning EDR studies within specific phases, researchers may be able to tell less of the overall story, but can then focus in on a narrow set of details that are valuable in their own right. 


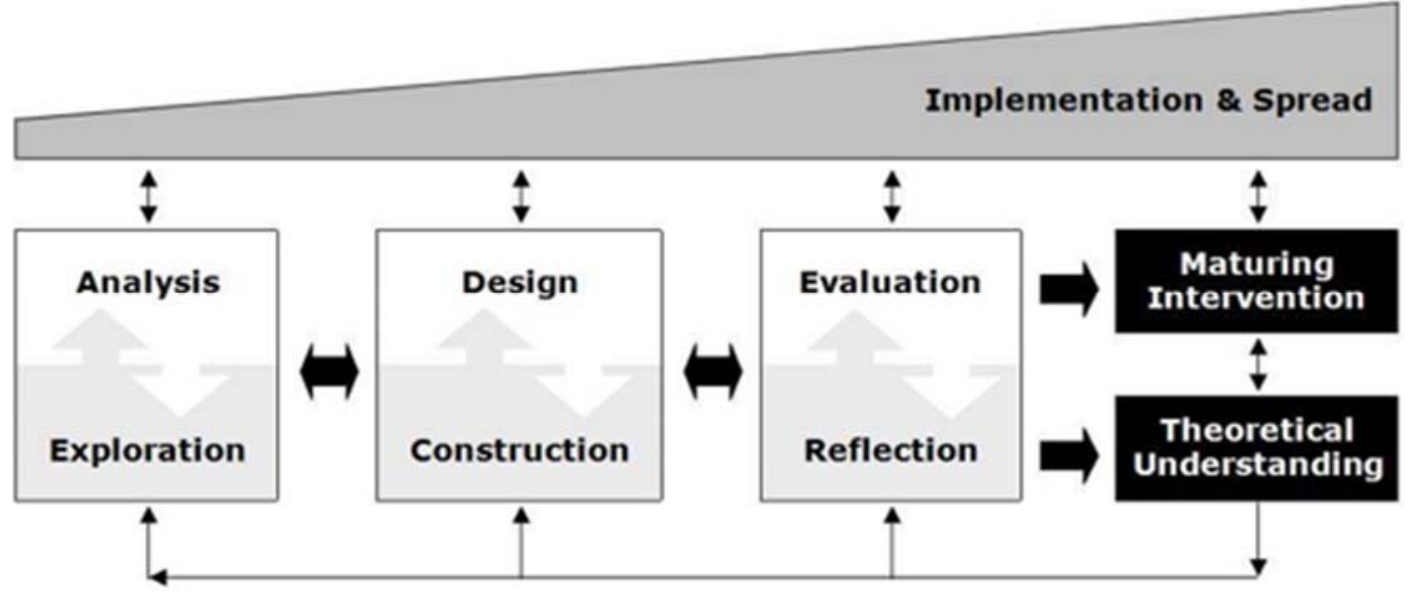

Figure 1. McKenney and Reeves (2012; p.159) generic model of Educational Design Research (EDR).

\section{Why this special issue?}

First, despite a surge of literature in the mid 2000s (e.g., Barab \& Squire, 2004; Bell, Hoadley, \& Linn, 2004; Reeves, Herrington, \& Oliver, 2005; van den Akker, Gravemeijer, McKenney, \& Nieveen, 2006), there remains uncertainty regarding the value and application of evidence produced through design research (Anderson \& Shattuck, 2012; Dede, 2004; Shavelson, Phillips, Towne, \& Feuer, 2003) and concern that research methodologies may lack the qualities associated with exclusively experimental methods (Reimann, 2011; Yoon, Duncan, Lee, Scarloss, \& Shapley, 2007). This uncertainty is not completely unwarranted. The quality of research within EDR studies can vary greatly from iteration to iteration, as well as case to case (McKenney \& Reeves, 2014; Reimann, 2011). Even though the same can be said for educational research in general, scholars remain skeptical that the potential of EDR can be fully realised. Thus, transparent examples of EDR are needed to fuel the discourse about the practical and scientific value of this approach.

Second, because EDR projects can span several iterations and contexts, they tend to generate a wealth of data and knowledge. They often address highly complex problems, for example by drawing on multiple theories of learning. This creates a unique challenge for educational design researchers with regard to scholarly publication. Namely, authors must present their studies in ways that conform to publication standards (including length of journal articles), yet also effectively communicate the salient details and complexities. EDR researchers can address this challenge by reporting project findings in relation to specific phases of an EDR project. But featuring the inherent value of phase-specific research often comes at the cost of describing the overall EDR project. As a result, phase-specific reports of EDR may be quite difficult to identify as such in the literature. Therefore, phase-specific reports of EDR that also portray the broader projects are needed to develop researcher capacity for disseminating EDR findings.

Third, the need for examples has increased in recent years. In response to the skepticism surrounding EDR and to advance the field, McKenney and Reeves $(2013,2014)$ and Reimann (2011) suggested the need for clear set of high quality EDR exemplars. Others have noted the need for examples to highlight the affordances of various design-oriented approaches (Nieveen, McKenney, \& van den Akker, 2006; Richey \& Klein, 2014). A particularly rare but much-needed kind of example is that which demonstrates systematic variation and testing of specific design features over repeated interventions. Through analytic generalisation, this can lead to the development of design principles and research exploring the extent of their application (McKenney \& Reeves, 2014; Reeves, 2011). Developing and sharing exemplars that are of high quality, portray rich variation, and clearly explore the extent and limits of generalisation constitutes an important step towards bridging the tension between research and design in a way that promotes innovative, research-based solutions to our educational problems that work in the real world.

The purpose of this special issue is to advance the field by showcasing exemplars of high quality EDR in post-secondary educational settings. We have sought manuscripts that detail EDR projects involving the 
use and/or development of educational technology in tertiary education (higher and further), lifelong learning, and training. This manuscript set therefore promotes research and scholarship on innovative instructional designs that integrate technology in those settings, promote effective practice, and help inform policy.

\section{Inside this special issue}

In this issue, readers are presented with an exciting variety of projects that aim to address substantial educational problems that arise in local contexts but whose core concerns are more universally experienced. Collectively, the six articles offer healthy diversity in terms of their maturity, with each presented as a snapshot of an EDR project at a specific point in time. Some are nascent projects just emerging with regard to their implementation and spread (see Figure 1). Generally speaking, these articles focus more strongly on exploring and establishing design principles (either from relevant theory or the practice of design) to be explored more fully in future iterations of the project. Other articles are more mature and represent snapshots of projects at a point of greater implementation and spread. These tend to focus on the study and evolution of design principles over repeated cycles of EDR and reflect on how those ideas have informed the theories guiding the project.

The six articles also explore the ways educational design researchers negotiate the challenges of representing their work within the various phases of EDR. EDR is a notoriously messy process that involves both the construction of an intervention and the research that comes from a sometimes overwhelming amount of data. In each article, the authors have addressed this messiness by clearly situating their work within one of the three EDR phases (i.e., analysis and exploration, design and construction, and/or evaluation and reflection). A risk this presents is that the phase distinctions may appear more clear or fixed than is the case in reality. It is important to note that no single phase stands alone. Rather, the phases of EDR interact with one another, like reciprocal ecosystems. The articles in this special issue serve as an example of how researchers can delicately establish boundaries for reporting EDR projects while at the same time communicating both explicitly and implicitly the connections between and across EDR project phases.

The authors of the articles in this special issue have also negotiated the potential tension that exists regarding the relationship between EDR as a genre of research and methodological commitments within particular EDR studies. EDR is an overarching approach that represents a broader ontological conceptualisation of what constitutes educational research; as such, it draws from multiple methods and methodologies including qualitative, quantitative, and mixed/multi-methods. The challenge this creates for educational design researchers is twofold. First researchers must select methods that are appropriate for the local context, educational problem, research questions, etc. Second, researchers must situate those study-specific methods within the general overarching EDR framework guiding their project in a way that is both logical and harmonious. Collectively, the authors of the articles in this special issue demonstrate a variety of ways in which this tension can be negotiated for the questions guiding their studies and within the context informing their research.

\section{About the articles}

The articles in the special issue are organised based on where they fall with regard to the spectrum of implementation and spread illustrated in Figure 1. We have established three points on this continuum that we feel represent the maturity of a given project. Those to the left represent projects that have just been adopted and are limited in respect to dissemination (e.g., workshops, publications) and diffusion (e.g., limited but promising evidence of value-added and broader application). Those in the middle more strongly explore the relationships between an intervention and how it is enacted within a broader scope of use. Finally, on the right of the spectrum are projects that have matured to a point in which they might sustain themselves and/or demonstrate strong levels of value added (e.g., publication record, multiple contexts). For more on implementation and spread, see McKenney and Reeves (2012).

The first two articles are situated at the left of the implementation and spread continuum. Each article details a single meso-cycle of EDR in which the authors begin establishing a relevant set of design principles that are embodied within a specific educational intervention. 
The first article, "In search of design principles for developing digital learning and performance support for a student design task”, by Lars Bollen, Hans van der Meij, Henny Leemkuil, and Susan McKenney of the University of Twente (Netherlands), is an example of an EDR project that explores design principles as emergent aspects of developing a novel technology-based instructional intervention. The study reports on the design and evaluation of a digital learning and performance support environment called TOM (based on the university's new didactical approach, the "Twente Educational Model"), which was used over 5 weeks to support 35 second-year psychology students performing a design task. Rather than a literaturebased design (Ormel, Roblin, McKenney, Voogt, \& Pieters, 2012), the authors used a data-driven design approach to derive key design principles that emerged from addressing a real and immediate instructional problem-that of supporting students in designing and prototyping a theoretically-informed interactive instructional intervention. The authors studied their process of design and development over a single phase of EDR using usability results and analysis of system logs to evaluate the impact of the environment on student perceptions and activities. The prominent outcome of this study is a set of three well-grounded design principles that will inform future design iterations. While this article is situated in the design and construction phase of EDR, the outcomes clearly have implications in the future for analysis and exploration as well as evaluation and reflection phases. Hence, this article serves as an exemplar of how the phases of EDR are both complementary and reciprocal.

The second article, "Re-designing university courses to support collaborative knowledge creation practices”, by Minna Lakkala, Auli Toom, Liisa Ilomäki, and Hanni Muukkkonen of The University of Helsinki, is an EDR project that examines how educational researchers engaged university lecturers in redesigning courses around a trialogical approach to learning (e.g., organising activities around shared objects, emphasising development and creativity, providing flexible tools for developing artifacts). This article stands in contrast with the first in that the authors use a literature-driven approach to their project activities, establishing a core set of design principles associated with collaborative knowledge creation at the outset of their project. Working closely with lecturers, the authors developed and conducted a series of workshops that aimed to introduce knowledge creation activities into university coursework. The study uses mixed methods to explore instructor and student reactions to three re-designed courses. Courses were purposefully selected so that they manifested the variation of design decisions lecturers could make as they integrated the design principles of trialogical approach in their specific courses. The authors then use the knowledge generated from the data to solidify the embodiment of those design principles in their overall design. The article is well situated in the evaluation and reflection phase of EDR; however, it also clearly communicates how this phase is directly informed by both of the previous phases.

The next three articles present EDR studies that span multiple meso-cycles of EDR, and are situated towards the middle of the spectrum of implementation and spread. In each, the authors offer highly detailed accounts of the ways in which researchers move through each of the phases of EDR in an effort to refine the tool itself and the theories upon which the tool was built.

The article, “Exploring college students' online help-seeking behavior in a flipped classroom with a webbased help-seeking tool”, by Erkan Er, Theodore J. Kopcha, and Michael Orey of the University of Georgia, and Wendy Dustman of Georgia Gwinnett College, reports on the design, development, and evaluation of an online help-seeking tool named EchoLu. Written from the perspective of the evaluation and reflection phase of EDR, the authors describe the development of the EchoLu tool for use in a post-secondary, large enrollment, flipped science classroom. EchoLu was designed to provide students with a means to seek help online when they are outside the classroom because students need additional support in classes that use the flipped classroom blended instructional model. To guide the initial design of EchoLu, the authors identified four design principles from the literature. These design principles were explored and refined over three meso-cycles of EDR. Results from two mixed-methods studies that utilised questionnaires to investigate students' help-seeking behaviors (387 and 356 students, respectively) are provided, with a highly focused explanation of not only how the intervention evolved based on iterative design cycles but also how theory was informed. In addition, the clear and cogent manner in which the authors connect theory and design in this article is outstanding. To be sure, maintaining clarity when writing up educational design research is daunting. Yet these authors are able to distinctly articulate their work by using a remarkably uncomplicated and lucid article structure to discuss complicated and sometimes ambiguous processes. Researchers may find this article particularly helpful for guidance in structuring their own EDR manuscripts. 
The article, "Professional learning in higher education: Understanding how academics interpret student feedback and access resources to improve their teaching”, by Jen Scott Curwood, Martin Tomitsch, Kate Thomson, and Graham D. Hendry of The University of Sydney, presents a novel approach to providing professional learning to academics. Drawing on theories of situated cognition, the authors engaged in three phases of design-based research on an interactive online environment called Ask Charlie. This environment is unique in that it was developed to provide personalised, just-in-time resources and instructional support to university faculty based on student evaluation of teaching data. Over a five year period, the authors collected a variety of data (e.g., interview, survey, focus group) from academics across multiple disciplines to conduct evaluation and research on Ask Charlie. The findings reveal key insights into the design and development of an online environment that addresses important issues in professional learning to academics. This article stands out as an exemplar in several ways. To begin, the authors make effective use of visuals to clearly articulate the complexity of their design with regard to the tool as well as the research. In addition, the article concludes with the authors connecting back to the theory upon which the tool was built. By returning to their original theory and design principles, the article offers other designers practical yet well-supported recommendations for providing quality resources to academics that directly address student feedback.

The article, "R-NEST: Design-based research for technology-enhanced reflective practice in initial teacher education”, by Bonnie Thompson Long and Tony Hall of the School of Education, National University of Ireland, Galway, describes a more longitudinal EDR effort in which digital storytelling was explored over 6 years as a means to enhance pre-service teachers' reflective practice. Over the course of three design cycles, the authors developed both a digital storytelling intervention and a theoretical model for using digital storytelling to enhance pre-service teachers' reflection on practice, called R-NEST. The project is well grounded in the literature with the theoretical underpinnings of the digital storytelling approach actually being used as an acronym for their project: reflection, narrative, engagement, sociality, and technology (RNEST). Altogether, each meso-cycle reported in this article covers all three phases in the EDR spectrum of maturity, from analysis and exploration through design and construction to evaluation and reflection. A particular strength of this article is how it shows clear progression along the EDR continuum of implementation and spread in that it started as a small pilot study (meso-cycle $1, N=18$ ), the results of which were used to improve both the intervention and theoretical assumptions, then moved into a larger mainstreaming effort (meso-cycle 2, $N=143$ ) with a focus on scaling the intervention so as to benefit more students, and finally was incorporated formally into an educational curriculum as a credit-bearing assignment (meso-cycle 3, $N=162$ ). After each evaluation, the authors reflect on their analyses, providing principled discussion regarding additions and enhancements to their underlying theoretical approach. As such, this article stands as an excellent example of using the EDR process to scale from prototype to fullscale implementation, with outstanding descriptions of both a maturing intervention and consistently improving theoretical understanding.

The final article, "Conjecture mapping to optimize the educational design research process", by Helen Wozniak of Flinders University, Australia, details an EDR project that is situated more towards the right of the spectrum of implementation and spread. This article differs from the other articles in the special issue in both breadth and scope. In particular, this article details a more mature EDR project that establishes a set of design principles from data collected over multiple iterations and across multiple contexts. Drawing on multiple theories of online learning and community building, Wozniak identified four design principles for supporting the problems associated with adult learners transitioning to online learning. The principles were then used to develop an online orientation program called Getting-on-Track, which was tested over multiple phases of EDR in two separate contexts over a five year period. A remarkable feature of this article is the use of a conjecture map (Sandoval, 2014) to ground the project activity. As a result, the article clearly details and communicates the ways in which key design principles were enacted and refined within the educational intervention. With five iterations of research conducted in two different contexts, the article offers insight into the ways an intervention matures and spreads over time. With that, it also offers an example of how EDR can be used to conduct analytic generalisation. Comparisons made across iterations and between contexts strongly inform the broader theory upon which the intervention was built. At the same time, those comparisons provide designers of online learning with well-established principles upon which to ground the design and study of similar interventions.

The special issue concludes with a contribution from Thomas Reeves, Professor Emeritus at The University of Georgia. In this concluding reflection, "Educational design research: Signs of progress”, Reeves looks 
across the six articles in the special issue to identify both their unique contributions to EDR as well as the commonalities among them. The author brings to light the importance of EDR as an approach to research by juxtaposing a media comparison study that used an experimental design with how educational design researchers might approach this same research project. Further, Reeves argues for educational design researchers to develop a longer-term shared agenda, similar to how the human genome project and the United Nations have developed shared agendas. He is convincing in his stance that this kind of approach can help achieve significant impact on a broad range of real educational problems.

\section{Conclusion}

While it is clear that EDR continues to gain exposure and popularity, it presents simultaneously a variety of challenges for most educational researchers. Our goal with this special issue was to present a set of exemplary EDR projects that can fuel discussion about the value and quality of this genre of research; demonstrate how phase-specific reports can be undertaken; and portray variation in methods, claims and generalisability. We consider the studies in this issue exemplary not because of a rigid adherence to specific methods (i.e., experimental, quasi-experimental, correlational, survey, etc.). Rather, we view these studies as exemplary because they have risen to what Fishman, Penuel, Allen, Cheung and Sabelli (2013; p. 136) characterise as the "[challenge] ... to transcend traditional research/practice barriers to facilitate the design of educational interventions that are effective, sustainable, and scalable." And at the same time, their methodological rigor renders the investigations transparent and the findings credible. These papers clearly approach issues of how, when, and under what conditions interventions are successful for their intended audiences. These are questions that plague many educational researchers (Fishman et al., 2013; Gutiérrez \& Penuel, 2014; Reeves, McKenney, \& Herrington, 2011; Winn, 2003) as well as those who design the curricular resources, assessments and professional development opportunities that touch practice directly (McKenney \& Schunn, 2015).

Though not on the scale suggested by Reeves, this special issue did emerge from a modest effort to bring members of the EDR community together. At a conference in 2013, structured on Johnston and Settlage's Crossroads model (2006, 2008, 2014), researchers gathered together to share their dilemmas with conducting EDR and discuss alternate perspectives on their problems, as well as potential solutions. The conference (http://dbrxroads.coe.uga.edu/) made a step toward serving researcher needs for collaborative incubation of ideas related to key challenges in EDR trajectories. Attendees also expressed the need for exemplars of EDR across the spectrum of maturity that also held up to rigorous peer review (our response to which has been this special issue).

Given these developments, it would seem that the field is now fertile for taking up the recommendation given by Reeves. We fully agree that coordination of efforts has the potential to increase depth, rigour and relevance of EDR scholarship in general, and within the ASCILITE community in particular. We offer our own time in helping develop a shared research agenda around EDR and encourage initiatives from others in carrying this notion forward. Together, let us demonstrate what a shared research agenda for EDR might look like, by beginning with an agenda focusing on issues dear to the AJET readership: educational technology for higher education.

The work of developing the body of EDR literature is just begun. We have learned much from working very closely with the authors in this special issue, especially through efforts to elucidate the exemplary characteristics of each EDR project reported here. We hope that the AJET readership will find this issue as helpful as we have found the process of bringing it to fruition. When it comes to EDR for educational technology in higher education, this issue may be a first of its kind. We hope that the articles presented here help promulgate increased submissions of EDR manuscripts to this journal, as well as others, and look forward to continued discourse around this promising yet challenging genre of inquiry.

\section{References}

Anderson, T., \& Shattuck, J. (2012). Design-based research a decade of progress in education research? Educational researcher, 41(1), 16-25. doi:10.3102/0013189X11428813

Bakah, M. A. B., Voogt, J. M., \& Pieters, J. M. (2012). Advancing perspectives of sustainability and large-scale implementation of design teams in Ghana's polytechnics: Issues and opportunities. 
International Journal of Educational Development, 32(6), 787-796. doi:10.1016/j.ijedudev.2011.11.002

Barab, S. A., Sadler, T. D., Heiselt, C., Hickey, D., \& Zuiker, S. (2007). Relating narrative, inquiry, and inscriptions: Supporting consequential play. Journal of Science Education and Technology, 16(1), 5982. doi:10.1007/s10956-006-9033-3

Barab, S. A., \& Squire, K. (2004). Design-based research: Putting a stake in the ground. The Journal of the Learning Sciences, 13(1), 1-14. doi:10.1207/s15327809jls1301_1

Bell, P., Hoadley, C. M., \& Linn, M. C. (2004). Design-based research in education. Internet Environments for Science Education, 73-85.

Dede, C. (2004). If design-based research is the answer, what is the question? A commentary on Collins, Joseph, and Bielaczyc; diSessa and Cobb; and Fishman, Marx, Blumenthal, Krajcik, and Soloway in the JLS Special Issue on design-based research. The Journal of the Learning Sciences, 13(1), 105-114. doi:10.1207/s15327809jls1301_5

Fishman, B. J., Penuel, W. R., Allen, A. R., Cheng, B. H., \& Sabelli, N. (2013). Design-based implementation research: An emerging model for transforming the relationship of research and practice. National Society for the Study of Education Yearbook, 112(2), 136-156. Retreived from http://nsse-chicago.org/Free/26_3092.pdf

Gutiérrez, K. D., \& Penuel, W. R. (2014). Relevance to practice as a criterion for rigor. Educational Researcher, 43(1), 19-23. doi:10.3102/0013189X13520289

Herrington, J., \& Oliver, R. (2000). An instructional design framework for authentic learning environments. Educational Technology Research and Development, 48(3), 23-48. doi:10.1007/BF02319856

Johnston, A., \& Settlage, J. (2006). Science education at the crossroads. Paper presented at the Annual Meeting of the Association for Science Teacher Education, Portland, OR.

Johnston, A., \& Settlage, J. (2008). Framing the professional development of members of the science teacher education community. Journal of Science Teacher Education, 19(6), 513-521. doi:10.1007/s10972-008-9112-9

McKenney, S., \& Reeves, T. C. (2012). Conducting educational design research. London: Routledge.

McKenney, S., \& Reeves, T. C. (2013). Systematic review of design-based research progress: Is a little knowledge a dangerous thing? Educational Researcher, 42(2), 97-100. doi:10.3102/0013189X12463781

McKenney, S., \& Reeves, T. C. (2014). Educational design research. In Spector, J. M., Merrill, M. D., \& Elen, J. (Eds.), Handbook of Research on Educational Communications and Technology, 4th ed. New York, NY: Lawrence Erlbaum Associates.

McKenney, S., \& Schunn, C. (2015). The crucial function and research needs of educational designers. Manuscript submitted for publication.

Nieveen, N., McKenney, S., \& van den Akker, J. (2006). Educational design research: The value of variety. In J. Van den Akker, K. Gravemeijer, S. McKenney \& N. Nieveen (Eds.), Educational Design Research (pp. 151-158). London: Routledge. doi:10.4324/9780203088364

Ormel, B. J., Roblin, N. N. P., McKenney, S. E., Voogt, J. M., \& Pieters, J. M. (2012). Research-practice interactions as reported in recent design studies: Still promising, still hazy. Educational technology research and development, 60(6), 967-986. doi:日0.1007/s11423-012-9261-6

Penuel, W. R., Fishman, B. J., Cheng, B. H., \& Sabelli, N. (2011). Organizing research and development at the intersection of learning, implementation, and design. Educational Researcher, 40(7), 331-337. doi:10.3102/0013189X11421826

Raval, H., McKenney, S., \& Pieters, J. (2010). A conceptual model for supporting para-teacher learning in an Indian NGO. Studies in Continuing Education, 32(3), 217-234. doi:10.1080/0158037X.2010.515571

Reeves, T. C. (2011). Can educational research be both rigorous and relevant? Educational Designer, 1(4). Retrieved from http://www.educationaldesigner.org/ed/volume1/issue4/article13

Reeves, T. C., Herrington, J., \& Oliver, R. (2005). Design research: A socially responsible approach to instructional technology research in higher education. Journal of Computing in Higher Education, 16(2), 96-115. doi:10.1007/BF02961476

Reeves, T. C., McKenney, S., \& Herrington, J. (2011). Publishing and perishing: The critical importance of educational design research. Australian Journal of Educational Technology, 27(1), 55-65. Retrieved from: http://ajet.org.au/index.php/AJET/article/view/982 
Reimann, P. (2011). Design-based research. In L. Markauskaite, P. Freebody, \& J. Irwin (Eds.), Methodological Choice and Design (pp. 37-50). Springer Netherlands. doi:10.1007/978-90-481-893353

Richey, R. C., \& Klein, J. D. (2014). Design and development research. In Handbook of Research on Educational Communications and Technology (pp. 141-150). New York, NY: Springer.

Sandoval, W. (2014). Conjecture mapping: An approach to systematic educational design research. Journal of the Learning Sciences, 23(1), 1-19. doi:10.1080/10508406.2013.778204

Settlage, J., \& Johnston, A. (2014). The crossroads model. Educational Leadership, 71(8), 67-70. Retrieved from: http:/www.ascd.org/publications/educational-leadership/may14/vol71/num08/TheCrossroads-Model.aspx

Shavelson, R. J., Phillips, D. C., Towne, L., \& Feuer, M. J. (2003). On the science of education design studies. Educational Researcher, 32(1), 25 -28. doi:10.3102/0013189X032001025

van den Akker, J., Gravemeijer, K., McKenney, S., \& Nieveen, N. (2006). Introducing educational design research. In J. Van den Akker, K. Gravemeijer, S. McKenney, \& N. Nieveen (Eds.), Educational Design Research (pp. 3-7). London: Routledge. doi:10.4324/9780203088364

Vanderhoven, E., Schellens, T., Valcke, M., \& Raes, A. (2014). How safe do teenagers behave on Facebook? An observational study. PLoS ONE 9(8): e104036. doi:10.1371/journal.pone.0104036

Winn, W. (2003). Research methods and types of evidence for research in educational technology. Educational Psychology Review, 15(4), 367-373. doi:1040-726X/03/1200-0367/0

Yoon, K. S., Duncan, T., Lee, S. W-Y., Scarloss, B., \& Shapley, K. (2007). Reviewing the evidence on how teacher professional development affects student achievement. Washington, DC: National Center for Education Evaluation and Regional Assistance. Retreived from: http://ies.ed.gov/ncee/edlabs

Australasian Journal of Educational Technology (c) 2015.

Please cite as: Kopcha, T. J., Schmidt, M. M., \& McKenney, S. (2015). Editorial 31(5): Preface to the Special Issue. In T. J. Kopcha, M. Schmidt, \& S. McKenney (Eds.), Educational design research in post-secondary learning environments. Australasian Journal of Educational Technology, 31(5), i-ix.

\section{Editors, Special Issue:}

\section{Dr. Theodore J. (TJ) Kopcha}

Associate Professor of Learning, Design, and Technology

Dept. of Career and Information Studies, The University of Georgia

850 College Station Rd, Athens, Georgia, 30605

Email: tjkopcha@uga.edu

TJ has over a decade of experience with teaching and consulting in both higher education and K-12 settings, including research and evaluation projects. In 2011, the American Association of Colleges of Teacher Education (AACTE) nationally recognised the innovative nature of his work in preservice teacher education, which was largely developed and studied through EDR. He currently has several publications that detail the use of EDR to examine technology enhanced cognitive apprenticeships in pre- and inservice teacher education. He has also taught on EDR at the doctoral level. More recently, he convened an AERA-funded research conference where educational designers from a variety of fields (e.g., STEM fields, educational technology, medical education, literacy education) met to advance the quality and rigor of DBR (http://dbrxroads.coe.uga.edu). He continues to employ EDR on several current projects, including the development of a STEM-integrated robotics curriculum (see projects at http://rail.coe.uga.edu). TJ serves as a reviewer for Educational Technology Research and Development, Computers and Education, and the International Journal of Learning in Higher Education. 
Dr. Matthew M. Schmidt

Assistant Professor of Instructional Design and Technology

University of Cincinnati

610 G Teachers College

Cincinnati, Ohio 45221, USA

Email: matthew.schmidt@uc.edu

Web: http://www.matthewschmidt.info

Matt has extensive research, teaching, and consulting experience in both the K-12 and higher education sectors. He has published widely in the fields of educational technology, online learning, and special education, with nearly 40 refereed publications to his name. Matt's research agenda focuses broadly on educational technology in K-12 special education, with specific research interests in games, simulations and virtual environments for students with autism spectrum disorders; mobile learning with pre- and in-service special education teachers; and distance supervision for special education teacher interns working in rural settings. His recent work takes an educational design research approach for developing a framework for special education teachers to integrate mobile technologies into their teaching and curricula. Matt serves as a reviewer for several journals including the Journal of Special Education Technology, British Journal of Educational Technology, Computers \& Education, Computers in Human Behavior, and the Australasian Journal of Educational Technology.

Dr. Susan McKenney, Associate Professor

Department of Instructional Technology, University of Twente Fostering Effective, Efficient and Enjoyable Learning Group (FEEEL) at the Welten Institute, Open University of the Netherlands

Susan is an Associate Professor at the University of Twente and the Open University, both in the Netherlands. She is also a visiting professor in the Learning Sciences \& Policy Group at the University of Pittsburgh. She uses design research in her own work and recently co-wrote a book with Tom Reeves about how to conduct this exciting form of inquiry. She teaches courses on educational design (research) and is regularly invited to consult, lecture and share her experiences. Her interest in research-practice interactions has also played forth into her guest editorships of Pedagogische Studiën and Instructional Science. After years of serving as editor-in-chief for the journal, Educational Designer, she currently serves as executive chair of its sponsoring organisation, the International Society for Design and Development in Education (http://www.isdde.org), a community that serves the needs of scientifically-informed educational designers. 